\title{
ESTADO Y PRODUCCIÓN: LA ACTIVIDAD YERBATERA EN EL TERRITORIO NACIONAL DE MISIONES (1926- 1953)
}

\author{
State and agrarian production. Yerba mate's plantations in national territory of \\ Misiones, Argentina (1926 - 1953)
}

\section{Lisandro R. Rodríguez*}

\section{Resumen}

La propuesta de este artículo es analizar la actividad yerbatera en Misiones, desde el decreto de residencia firmado por el presidente Marcelo T. de Alvear en 1926 hasta la provincialización del Territorio en 1953. El objetivo es interpretar las acciones del Estado -en tanto prácticas que apuntan a controlar las actividades económicas, políticas y sociales- en un área de triple frontera; particularmente las relacionadas con la yerba mate. Se tendrán en cuenta los ciclos productivos, las formas de intervención y regulación estatal -a través de instituciones como la Comisión Reguladora de la Yerba Mate (CRYM)- con el propósito de reconocer quiénes las formularon, hacia quiénes fueron dirigidas y cuáles fueron sus consecuencias.

$$
<\text { Estado }><\text { Producción yerbatera }><\text { Inmigración }>
$$

\begin{abstract}
This paper analyzes the activities related to yerba mate production in Misiones, National Territory located in Northeastern Argentina, between 1926 and 1953, i.e., when this territory was affected by the residence order signed by President Marcelo T. de Alvear until the provincial period was initiated in 1953. The aim of this investigation is to recognize the implications of state actions such as practices to control the social, economical and political activities, in this border area; specially those policies related to yerba mate production. The characteristics of the productive cycles, and the ways of state intervention and regulation (by means of the Comisión Reguladora de la Yerba Mate, CRYM) are considered elemental issues when trying to recognize who were the policymakers, for whom the policies were addressed and what were the consequences of these policies.
\end{abstract}

$<$ State $><$ Yerba Mate's production $><$ inmigration $>$

Recibido: 2/07/13 // Aceptado: 20/10/14

\footnotetext{
* Profesor en Historia, Pertenencia Institucional: Becario CONICET/ UNQ- CEAR, lisandrodriguez@gmail.com
} 
Rodríguez. Estado y producción: la actividad yerbatera en el territorio nacional de Misiones (1926- 1953)

\section{1.- La yerba mate y la conformación de la estructura agraria misionera}

La producción de yerba mate ${ }^{1}$ en la República Argentina está circunscripta al extremo Nordeste del país, ${ }^{2}$ más específicamente a las provincias de Misiones y Corrientes, siendo la distribución entre ambas asimétrica debido a factores históricos (De Sagastizabal, 1984; Stluzki, 2011). El 90\% de la producción se sitúa en Misiones y el $10 \%$ restante en Corrientes. Esta actividad -de importancia social y económicaademás de presentar un alto índice de consumo, genera ingresos por ventas; movilizando tanto a productores como al sector industrial y comercial.

La actual provincia fronteriza de Misiones formó parte de varias experiencias históricas, que plasmaron un territorio muy diverso: la etapa guaraní (de pueblos originarios); el periodo jesuítico (1608-1768); la anexión territorial a la Provincia de Corrientes (1831- 1881); la etapa Territoriana (1881- 1953), ${ }^{3}$ cuando el Poder Ejecutivo Nacional desplaza la "tutela" que la Provincia de Corrientes ${ }^{4}$ ejercía sobre Misiones y toma la responsabilidad política de crear y darle entidad al territorio a partir de una nueva figura: los Territorios Nacionales ${ }^{5}$. Además, durante el siglo XX cumplió el rol de frontera agraria, es decir, como espacio abierto para atraer inmigrantes en busca de oportunidades de ascenso social (Baranger, 2000). La última etapa corresponde al periodo provincial (1953 a la actualidad). Estas experiencias conformaron la construcción social de un territorio heterogéneo en su organización económico- social, que muchas veces escapó a las fronteras físicas o políticas, constituyendo un espacio en constante dinamismo (Manzanal, 2014). El Consejo Federal de Inversiones (CFI), ${ }^{6}$ definió distintos periodos para analizar la estructura agraria misionera. El marco temporal propuesto en este estudio se corresponde con las dos primeras etapas:

1 Planta perteneciente a la especie ilex paraguariensis y producto que se obtiene a partir de la misma. Además de Argentina, son productores de yerba mate Brasil y Paraguay.

2 La temperatura, humedad y composición del suelo de esta región son propicias para el cultivo de yerba mate (Gortari, 2007).

3 La importancia de los Territorios Nacionales para el Ejecutivo Nacional se puede percibir en discursos oficiales, como por ejemplo el del Presidente de Agustín P. Justo quien manifestaba: "el progreso de los territorios, mediante la leal política de las normas de gobierno y la seguridad y mejoramiento de las condiciones de vida de sus habitantes ha constituido una constante preocupación del Poder Ejecutivo". Más adelante en el mismo documento se aprecia “... el Ministerio del Interior adoptó, en una oportunidad, las medidas tendientes a depurar la organización policial de los territorios, aumentando, asimismo, sus efectivos" (Justo, 1937- Cárcano, 1972).

${ }_{4}$ Previo a la Nacionalización, el gobierno de Corrientes decide vender grandes cantidades de tierras de Misiones a emprendimientos privados, un error de mesura sobre el territorio permitió recuperar tierras que serían destinados al proceso de colonización oficial.

5 El espacio definido como Territorio Nacional, además de ser un criterio divisional para denominar a un espacio que no había adquirido el rango de provincia, representa una organización política y económica caracterizada por una heterogeneidad, una desigualdad económica (periferia) y política, (ciudadanía limitada). Compartían este status además de Misiones, Chaco, Formosa, La Pampa y los territorios de la Patagonia (Ruffini, 2007).

6 Para un análisis de las distintas etapas ver CFI (1975); además Slutzky Daniel (2011) Estructura social agraria y agroindustrial del nordeste de la Argentina: desde la incorporación a la economía nacional al actual subdesarrollo concentrador y excluyente. Instituto Argentino de Desarrollo Económico (IADE). 
1) Se extiende desde 1880 a 1935 cuando se conforma la matriz social agraria a través del proceso de inmigración y colonización. Las actividades agrícolas pasaron a ser dominantes en la economía de Misiones; la integración al mercado nacional se dio a través de un producto complementario a los de la pampa húmeda: la yerba mate, ${ }^{7}$ que constituyó el "cultivo poblador" y favoreció la integración de los colonos a la sociedad nacional, puesto que los obligó a relacionarse con el mercado, a operar en el sistema crediticio y a utilizar el idioma oficial (Bartolomé, 1975 y 1982).

2) Desde 1935 hasta 1955 aproximadamente el rasgo principal es la consolidación de la pequeña y mediana explotación agrícola, en un marco político y económico propicio, caracterizado por la regulación estatal de la producción yerbatera, a través de la Comisión Reguladora de la Yerba Mate y la incorporación del tung como cultivo dinamizador. Se define así un carácter agroindustrial en la economía misionera. El contexto posibilita cierto grado de capitalización, así como la consolidación y expansión de un movimiento cooperativista importante. ${ }^{8}$

\section{1- La yerba mate como cultivo colonizador y de acceso a la tierra}

La yerba mate es la vía tradicional de constitución de los colonos y de su acceso a la tierra en Misiones. La implantación de este cultivo constituye el primer escalón en la carrera de ocupante a colono aunque no todos los productores logran el paso de un estrato social a otro. Además, la conformación del tipo social agrario está determinada por el mercado. La incorporación de la yerba mate como producto de comercialización originó la formación de agricultores comerciales, "el patrón de explotación mixta y diversificada fue abandonado en favor del cultivo de la yerba mate y la vida entera de la región quedó vinculada a la evolución de este cultivo". A partir de entonces, el "colono" representa una trayectoria social ascendente (Schiavoni, 1995).

La actividad yerbatera reconoce antecedentes históricos. ${ }^{9}$ La finalización de la Guerra de la Triple Alianza (1865-1870), significó la apertura de un espacio económicamente nuevo para la penetración capitalista e implicó cambios en la organización política y económica del conjunto regional que involucra a Paraguay, Brasil y Argentina. Al mismo tiempo, significó la pérdida del control paraguayo del mercado

\footnotetext{
7 El monocultivo como motor económico se registra en otras economías regionales. La expansión del ferrocarril a la provincia de Tucumán en 1876 y la consecuente apertura de inversión de capitales, el crédito oficial y una ventajosa política fiscal conllevaron a la modernización de la industria azucarera. A partir de este proceso, esta actividad se convierte en el sostén de la economía regional del noroeste argentino, reemplazando al, hasta entonces, principal cultivo: el maíz. Como en el caso misionero, la integración al mercado nacional se da sobre la base de una producción primaria no competitiva con la Pampa Húmeda (Girbal Blacha, 1995).

8 Entre 1926 y 1946 se crearon las cooperativas Agrícola Tabacalera y Yerbatera Rincón de Bonpland; Olegario V Andrade; Agrícola Ltda. De Oberá; Agrícola de Picada Libertad; Agrícola Mixta de Montecarlo; Agrícola de El Dorado; Agrícola de Puerto Rico; Productores yerbateros de Santo Pipó; Agrícola Ltda de Oro Verde; Agrícola Mixta de Misiones; Gobernador Roca; Santo Pipó Tung Oil; Agrícola de Santo Pipó que nucleaban a más de 7.500 productores agrícolas (Amable, et al 2011).

9 Para un mayor análisis ver: Kaner, M. 1999. Apuntes históricos sobre la yerba mate. Posadas. Editorial Universitaria UNAM.
} 
Rodríguez. Estado y producción: la actividad yerbatera en el territorio nacional de Misiones (1926- 1953)

de la yerba mate y porciones de territorios ricos en yerbales y bosques naturales que pasaron a manos de Brasil (Matto Grosso) y a la Confederación Argentina (Misiones y Chaco) (Alcaraz, 2010). Empero, es en la década de 1920 cuando comienza a cobrar mayor importancia al dejar de ser extractivista ${ }^{10}$ para convertirse en una actividad agrícola $^{11}$ dando inicio a la industria yerbatera, que demandará mayores inversiones de capital, incorporación de nuevas tecnologías y renovadas formas de organización del trabajo agrario ${ }^{12}$ (Rau, 2012).

El proceso colonizador impulsado por el Estado Nacional en la zona sur y centro del territorio (entre 1880-1930) y organizado a través de empresas de capitales privados en el Alto Paraná (a partir de 1920) establece condiciones favorables para la adquisición de tierras fiscales y privadas. Se consolida así la pequeña y mediana producción agrícola $y$, en las zonas de frontera agrícola, de mayor dinamismo, la ocupación espontánea ha dejado como resultado un número considerable de "ocupantes" de tierras fiscales o privadas (Schiavoni, 1995). Además, modela el paisaje misionero (Bolsi, 1986) e implica el avance estatal sobre un área de frontera. Este aspecto resulta fundamental para resaltar la originalidad del estudio propuesto, al ser el único territorio fronterizo que se coloniza con yerba mate. En Brasil, la existencia de este cultivo no devino en un proceso colonizador y poblacional. El avance sobre los territorios con presencia de yerba mate estuvo en manos de compañías privadas como la Matte Larangeira ${ }^{13}$ :

"Al final del siglo XIX y principios del XX, la región del Matto Grosso do Sul, se convertirá en objeto de inversiones exploratorias de la hierba mate, natural de allí y abundante, actividad que no preveía fijación poblacional. Terminado el conflicto bélico entre Brasil y Paraguay una única empresa, la Companhia Matte Larangeira, arrendó y monopolizó tierras que se extendían del Río das Onças e incluyan los ríos Dourados,

\footnotetext{
${ }^{10}$ Durante la etapa del frente extractivo actuaban en el territorio tres frentes económicos: al norte un frente centrado en la explotación de los grandes yerbales y montes naturales; al sur, en la zona de campos, se extendía un frente ganadero que tenía las mismas características que la ganadería de Corrientes y en la zona donde habían estado las antiguas Misiones se extendía la producción agrícola a pequeña escala (Schvorer, 2011).

${ }^{11}$ La actividad yerbatera se puede dividir en dos etapas: a) Etapa de apropiación de la yerba en estado natural o silvestre, que comienza en 1875 con la habilitación de la extracción en la región de la actual Misiones, coincidente con el denominado frente extractivo; b) Etapa de plantación y producción que se extiende desde 1903 hasta la actualidad. A esta cronología se le puede anteceder el uso que les daban los guaraníes y posteriormente los jesuitas.

${ }^{12}$ Para un análisis de las condiciones de trabajo ver Niklison, Elías (1914) Informe sobre las condiciones de trabajo en el Alto Paraná. Boletín del departamento Nacional del Trabajo $\mathrm{N}^{\circ} 26$. Buenos Aires. Ministerio del Interior.

${ }^{13}$ Sociedad anónima fundada en Río de Janeiro en 1891 con el objetivo de explorar los yerbales nativos de la porción sur del estado brasileño de Matto Grosso. Organizó en esa época un vasto circuito mercantil, integrando áreas de producción y consumo. La fase más conocida de ese circuito envolvía al Matto Grosso y a la Argentina (principal mercado consumidor) y consistía en flujos de importación, de géneros de consumo, de trabajadores y exportación de yerba canchada en cooperación con una firma bonaerense: Francisco Méndez y Cia. Este circuito se realizaba a través de una extensa utilización del sistema fluvial platino, sobre todo los ríos Paraná y Paraguay (Queiroz, 2012).
} 
Brilhante, Ivinhema, Paraná e Iguatemi. Con derechos exclusivos y poderes para obstruir la entrada y la permanencia de colonos o competidores, la Cia. Matte contribuyó, sin saberlo o quererlo, para que la zona se mantuviese libre de la presencia intensa de blancos hasta los años 1920/30" (Tomaz de Almeida y Mura, 2004).

Entre los factores que posibilitaron la colonización del Territorio Nacional de Misiones se destaca la política de tierras -aunque la titularización no abarcó a todos los productores- con baja o nula imposición. A partir de 1926, por medio de un decreto firmado por el Presidente Marcelo T. Alvear, la Dirección Nacional de Tierras establece la obligación de residencia para las explotaciones adjudicadas y la plantación entre un $25 \%$ y $50 \%$ de la superficie con yerba mate. Los productores que plantaran yerba mate en un $75 \%$ del territorio adjudicado quedaban eximidos de la obligación de residencia, pero a cambio debían pagar un recargo en el precio de la tierra ${ }^{14}$. El tamaño de las explotaciones no fue homogéneo, aunque sobresalen las unidades de no más de 25 hectáreas. "La plantación del yerbal en pequeñas unidades generó explotaciones familiares con escaso capital y el uso de técnicas rudimentarias que enfrentaron a un aparato comercializador fuertemente concentrado" (Barsky, 2001).

"El examen de los mecanismos de apropiación de la tierra, y de los procesos de acumulación en las explotaciones familiares de Misiones, resulta inseparable de la consideración de la política de colonización (estatal y privada) y del tipo de desarrollo de la agricultura comercial (cultivos de rentabilidad cíclica). En términos generales, la estructura agraria de Misiones se caracteriza por el predominio de explotaciones medias y pequeñas, que coexisten junto a importantes latifundios y establecimientos reforestados y agroindustriales" (Schiavoni, 1995).

La distribución de la tierra fue establecida por el Reglamento de la Dirección General de Tierras:

Art. 798.-Las colonias yerbateras se fundarán exclusivamente en el Territorio de Misiones.

Art. 824.-Todas las colonias que se creen en Misiones o los lotes que en lo sucesivo se vendan, tendrán el carácter de yerbateros, subsistiendo para los concesionarios las obligaciones generales ya establecidas, para las colonias agrícolas, salvo lo dispuesto en el $\mathrm{N}^{\circ} 828$.

\footnotetext{
${ }^{14}$ La colonización yerbatera nació en el mismo centro del proceso de escisión radical. Sin embargo, en la toma de decisiones habrían pesado también quienes políticamente apoyaban el proteccionismo o quienes económicamente se verían beneficiados por esa protección y por la seguridad de contar con materia prima en forma abundante y continuada" (Bolsi, 1986).
} 
Art. 828.-Los concesionarios de lotes yerbateros en las condiciones del número anterior, estarán sujetos a las obligaciones adicionales siguientes:

a) Para los concesionarios de 25 hectáreas, cultivo del $50 \%$ del área con yerba mate, y aumento de un $5 \%$ sobre el precio normal de venta.

b) Para los concesionarios mayores de 25 hectáreas, hasta 50 hectáreas, cultivo del $50 \%$ de la superficie concedida y recargo de un $15 \%$ sobre el precio normal de venta.

c) Para concesiones de más de 50 hectáreas hasta 75 , cultivo del $75 \%$ de la superficie concedida, y recargo de un $25 \%$ sobre el precio normal de venta.

d) Para concesiones de 75 a 100 hectáreas, cultivo del $75 \%$ de la superficie concedida, y recargo de un $35 \%$ sobre el valor normal de venta.

Entonces, colonización y actividad yerbatera dan origen al tipo social agrario, asociado en este periodo con la figura del colono (Bartolomé, 1975) que se caracteriza por ser un productor agrícola que aprovecha las oportunidades de capitalización que ofrecía la economía agraria de Misiones. El origen y la experiencia histórica de los inmigrantes condicionan tanto su inserción en la sociedad como en la economía regional y lo definen como un tipo cultural específico. A su vez, dichos elementos modifican sustancialmente la sociedad misionera, conformando una sociedad heterogénea y multiétnica $^{15}$ (Abinzano, 1985).

El acceso a la tierra por parte de los inmigrantes permite enunciar ciertas diferencias entre Misiones de las demás economías regionales y que resaltan la originalidad de la colonización yerbatera. En la provincia de Mendoza por ejemplo, el acceso a la tierra por parte de los inmigrantes se dio por la expansión de la vitivinicultura durante 1880-1920, que originó una red particular de relaciones sociales de producción: el sistema de contratistas, mediante la incorporación de inmigrantes europeos al cultivo de los viñedos, que acentuó las diferencias entre criollos e inmigrantes facilitándole a estos últimos el acceso a la propiedad territorial y a altas tasas de ganancias, con una capitalización creciente que les permitió a algunos constituir -desde inicios del siglo XX- sociedades anónimas (Salvatore, 1986).

\section{2.- Ciclos yerbateros}

Los ciclos de la yerba mate (expansión o estancamiento por crisis o sobreproducción) determinaron en gran parte la organización del agro en Misiones (como ocurriera con el azúcar en Tucumán y los vinos en Mendoza). Se distinguen

\footnotetext{
${ }^{15}$ A diferencia de lo ocurrido en las zonas de colonización más antigua del país, los colonos misioneros provienen principalmente del norte y este de Europa, entre los que se destacan los alemanes, polacos y ucranianos. Además existen un número importante de escandinavos, suizos y franceses que dan lugar a la denominada sociedad multiétnica o tipo mosaico étnico (Schiavoni, 1995).
} 
tres fases para el período propuesto en este estudio: a) se extiende de 1910 a 1931 y es reconocido como el boom yerbatero, denominado ciclo del "oro verde"; b) abarca de 1935 a 1944 (primera etapa de intervención estatal a través de la CRYM), se caracteriza por ser un periodo favorable en relación al costo de producción y el precio de venta; y c) desde 1945 a 1955 en el que aumentan los costos de producción, más allá de las políticas dirigistas del peronismo (Bartolomé, 1975). Las distintas crisis en el sector generan ciclos que a su vez definen la composición y variación de las explotaciones agrícolas; generalmente determinan la implementación de nuevos cultivos como por ejemplo el tung, aunque la yerba mate continuó en todos los ciclos como el producto principal de la estructura agraria misionera.

Durante el "boom yerbatero" y sobre todo a partir de la década de 1920 la vida agrícola en Misiones crece en forma significativa; la superficie plantada con yerba mate pasa de 3.500 hectáreas a más de 65.000 en 1940. El ritmo de implantación, que oscilaba entre 700 y 800 mil unidades anuales en 1920, se incrementa hasta superar los 10 millones en 1927 y mantenerse entre 2 y 8 millones hasta 1935. La producción aumenta de menos de tres millones de kilos hasta 100 millones en 1937 para luego mantenerse -por algunos años- en cifras cercanas a los 70 millones. Paralelamente, el territorio misionero albergaba unas 63.000 personas en 1920 y en 1947 superaba las 246.000 habitantes (Bolsi, 1986).

El aumento constante de la actividad yerbatera nacional se debió, además, a los movimientos sociales que se desarrollaban en el sur de Brasil y en Paraguay desde las primeras décadas del siglo XX y que afectaban la comercialización de sus producciones. En este sentido, el despliegue de la producción nacional en Misiones devino en situaciones conflictivas, particularmente con Brasil, principal abastecedor de la Argentina desde el siglo XIX. Los productores brasileños tomarían medidas para proteger su exportación. El manejo de la bolsa de Curitiba fue una de las políticas implementadas acompañada por los intereses de la Cámara de Comercio Argentino- Brasileña, que no demostró ser imparcial, sino un instrumento de los yerbateros paranaenses. Entre los argumentos que sostenía (para privilegiar la yerba de Brasil en detrimento de la yerba misionera) destacaba "el gusto" del consumidor por un tipo específico de yerba, aludiendo a que, tanto la yerba paraguaya como la brasileña eran "exigidas por el consumidor, por lo que no queda otro camino que recurrir a la importación” (Bolsi, 1986).

El Estado argentino responde con una rebaja en los aranceles aduaneros ${ }^{16}$ a la entrada de yerba mate brasileña, hecho que va en detrimento del productor nacional. Además, favorece a los yerbateros de Brasil y al mismo tiempo a los molineros de la Argentina, que se beneficiaban con los bajos costos de la yerba extranjera (Barsky, 2001).Ante la situación de crisis, la producción argentina se ve obligada, como en otras

\footnotetext{
${ }^{16}$ Los aranceles aplicados en 1928 a la importación se refería a la yerba molida, pero no a la yerba canchada, prevaleciendo con ello los intereses de los molineros importadores por sobre el productor. Los precios no logran compensar los costos de producción y los plantadores pierden $\$ 0,04$ por cada kilo de yerba elaborada. En 1930 la yerba nacional cuesta $\$ 4,00$ los 10 kilos y la brasileña en virtud de su política, $\$ 2,65$. Para salvar parte de su capital los plantadores misioneros, se vieron forzados a vender sus cosechas a precios irrisorios (Schamber, 2000).
} 
oportunidades, a solicitar el amparo del Gobierno Nacional contra las maniobras, no siempre leales, de quienes se proclamaban sus adversarios.

"Entre la plantación argentina que sale a conquistar su propio mercado y la extranjera que intenta oponérsela, no hay acuerdo posible: el antagonismo no tendrá otra solución que la eliminación gradual de las yerbas extranjeras, a medida del crecimiento de las cosechas argentinas" (Daumas, 1930).

Existen antecedentes que demuestran que toda industria naciente obtiene derechos protectores, por ejemplo con el trigo (aunque fuera Brasil quien vendiera harina a los Estados Unidos).Sin embargo, con respecto a la industria yerbatera argentina los derechos permanecieron sin cambio alguno por 24 años, de 1900 a 1924, durante los cuales "nadie se acordó de ellos" (Coni, 1929). En este sentido, son muchos los intereses y posturas que intervinieron en esta producción. El gobernador de Misiones Dr. Héctor Barreyro (1922-1930) afirmaba que:

“... las yerbas extranjeras pagan en la actualidad, en que precisamente existe una verdadera industria yerbatera nacional que defender, un derecho de aduana inferior al que han venido pagando durante los treinta años que han precedido a la implantación del cultivo de la yerba mate en el país. Los productores de las yerbas del Brasil, ante la perspectiva de que dentro de algunos años se verán desalojados del mercado consumidor argentino, han organizado el "dumping", ${ }^{17}$ con el propósito de destruir nuestra industria" "Es así que esta Gobernación con todo el respeto debido, se permite sugerir a V.E. las medidas que, a su juicio, deberían adoptarse en defensa de los plantadores de yerba mate del país (...) supresión del decreto del Poder Ejecutivo del 24 de marzo de 1924, que rebajo los derechos aduaneros de la yerba mate en un 30\%" sobre los establecidos por la ley 11.228. Esta supresión disminuiría las ventajas actuales de la producción extranjera para la competencia en nuestro propio mercado". ${ }^{18}$

A pesar de la situación planteada, algunas posturas como la del Ministro de Agricultura Antonio De Tomaso aseguraban que la masiva entrada de yerba brasileña no constituía un dumping:

"Antes bien este desgraciado ensayo la colonización yerbatera

\footnotetext{
${ }^{17}$ Vender un producto por a un precio inferior a su valor con el objetivo de desplazar a la competencia.

${ }^{18}$ Revista de Economía Argentina: La industria yerbatera argentina. Informe del Gobernador de Misiones. Buenos Aires. $\mathrm{N}^{\circ} 117$ marzo de 1928 Ob. Cit. Pp. 223-224.
} 
y sus resultados ha perturbado las relaciones comerciales con el Brasil, que era comprador no desdeñable, porque no es desdeñable poder colocar 600.000 o 700.000 toneladas de trigo". ${ }^{19}$

Las discusiones se hicieron eco a nivel nacional y alcanzaron a las sesiones de la Cámara de Diputados de la Nación; donde en diciembre de 1924 el diputado demócrata progresista Lisandro de la Torre ${ }^{20}$ refiriéndose a la cuestión de la industria yerbatera afirmaba que:

“...El Poder Ejecutivo ha modificado la ley 11281 (Ley de Aduanas) por sí y ante sí, y ha concedido por un decreto de 24 de marzo pasado, una rebaja de 30 por ciento en los derechos de importación de las yerbas brasileñas. Es indudable que el Poder Ejecutivo carece de facultades para proceder así, porque no se reúnen en este caso que señalo los requisitos del artículo 76 de la ley de aduana. El Poder Ejecutivo, para justificarse, dijo en los fundamentos de su decreto que la industria harinera argentina había recibido grandes facilidades en el Brasil para la importación de sus productos, y que la misma industria yerbatera argentina resultaría beneficiada con la rebaja, porque ella determinaría la no aplicación de un adicional del 25 por ciento en la exportación de yerba que rige en el Brasil". ${ }^{21}$

La década de 1930 inaugura un nuevo tipo de Estado con fuertes rasgos intervencionista y que, "define una política más clara en obras públicas, como así también en el control de la producción y control de precios, para lo que crean las juntas reguladoras. ${ }^{22}$ Pero el Estado interventor actúa fundamentalmente en el terreno

${ }^{19}$ Ibídem.

${ }^{20}$ Lisandro de la Torre: Nació en Rosario el 6 de diciembre de 1868. Abogado. Doctor en jurisprudencia. Fue Diputado Nacional los años 1912- 1916 y entre 1922-1926. Senador Nacional de 1932-1937. En 1906 fundó en la provincia de Santa Fe el partido político Liga del Sud. Posteriormente dicho partido se denominó Demócrata Progresista. (Datos en Quién es Quién en la Argentina. Biografías contemporáneas. Buenos Aires. Editores Guillermo Kraft Ltda. 1939).

${ }^{21}$ Obras de Lisandro De La Torre. Tomo VI: Política Agraria y Municipal. Editorial Hemisferio. Buenos Aires. Segunda Edición. 1960.

${ }^{22}$ En el marco de la política intervencionista se crearon la Comisión Nacional del Azúcar (decreto $\mathrm{n}^{\circ} 702$ de 1928, pero sólo se constituyó el 2 de enero de 1931), Comisión Nacional de Fomento Industrial (decreto $\mathrm{N}^{\circ} 58$ del 15 de enero de 1931), Dirección Nacional de Elevadores de Granos ( N¹1.742 del 7 de octubre de 1933), Junta Nacional de Carnes (Ley 11.747 del 7 de octubre de 1933), Junta Reguladora de Granos (decreto $N^{\circ} 31.864$ del 28 de noviembre de 1933), Junta para Promover las Exportaciones de Carne (decreto $\mathrm{N}^{\circ} 46.299$ del 27 de julio de 1934, fue disuelta en 1937), Comisión Nacional de la Industria Vitivinícola (decreto $\mathrm{N}^{\circ} 46.837$ del 11 de agosto de 1934; la ley 12.137 del 24 de diciembre de 1934, crea la Junta Reguladora de Vinos), Junta Nacional para Combatir la Desocupación (ley N 11.896 del 21 de agosto de 1934), Comisión Nacional de Coordinación de Transporte (ley $\mathrm{N}^{\circ} 12.346$ del 5 de enero de 1937), Comisión de Control de Abastecimiento (decreto $\mathrm{N}^{\circ} 40.890$ del 8 de septiembre de 1939; 
Rodríguez. Estado y producción: la actividad yerbatera en el territorio nacional de Misiones (1926- 1953)

económico. Se trata todavía de un Estado que no distribuye socialmente la riqueza" (Quiroga, 1985). Los conflictos registrados son antecedentes directos para la creación de un instituto regulador, similar a las juntas reguladoras de Carnes, Granos, Azúcar, Algodón, Vinícola, de la primera mitad del decenio de 1930 que culminará en la creación -en 1935- de la Comisión Reguladora de la Yerba Mate (CRYM), precedidas por ciertas medidas tomadas por el Estado nacional, algunas de carácter bilateral con Brasil. Sobresalen las firmas del Tratado de Comercio y la Carta de Navegación ${ }^{23}$ de 1933, ratificados en 1935, previa visita recíproca de los mandatarios de la Argentina Agustín P. Justo y del Brasil Getulio Vargas (Vanderlei, 2008).

\section{3.- La Comisión Reguladora de la Yerba Mate (CRYM) ${ }^{24}$}

En los albores de la década de 1930, la decisión de los productores yerbateros del Brasil de inundar de yerba mate el mercado argentino mediante una baja de los precios, provoca, junto a la producción nacional, una sobreoferta en el mercado local. La situación obligó al Presidente Agustín P. Justo a tomar medidas para proteger al productor y regular la actividad nacional, intentando evitar un crecimiento desmesurado de la producción de este cultivo. Ante esta situación, por intermedio de la "Legislación General Ley $\mathrm{N}^{\circ} 12.236$ de 1935:

Art. $1^{\circ}$ : Crease con carácter autónomo la Comisión Reguladora de la Producción y Comercio de la Yerba Mate (...)

Art. $2^{\circ}$ : Esta Comisión será presidida por el Ministro de Agricultura o funcionario que éste designe y se compondrá de trece miembros nombrados por el Poder Ejecutivo, como sigue: el gobernador del territorio de Misiones, dos representantes de Ministerio de Agricultura, un representante del Banco de la Nación y otro del Banco Hipotecario Nacional, tres representantes de los plantadores, tres de los elaboradores, uno de los importadores y un representante de los consumidores". ${ }^{25}$

Entre sus principales funciones se destacaban:

a) Aplicar y hacer cumplir las leyes y decretos reglamentarios existentes y cualquiera otra disposición que se dicte.

b) Asesorar a los poderes públicos sobre todo a lo que se refiere a la materia de su cometido.

esta Comisión fue creada para hacer cumplir la ley 12.591 de precios máximos), Comisión Nacional de Granos y Elevadores (ley 12.253 del 5 de octubre de 1935).

${ }^{23}$ Este tratado contenía entre sus medidas más importantes la fijación, por parte de los países firmantes (Argentina- Brasil), de un modus vivendi en el que se comprometían a no proceder a ningún tipo de aumento sobre los derechos de importación, además se comprometieron a no ejercer prohibición a la importación o exportación. Por este tratado la Argentina también debía retroceder y anular la ley que establecía el $10 \%$ ad valorem sobre la yerba mate (Magán, 2008).

${ }^{24}$ La CRYM como ente de regulación funcionó desde el año 1935 hasta el año 1991, cuando por decreto del gobierno nacional la actividad yerbatera se desregulariza y la institución desaparece, poniendo fin a más de medio siglo de intervención estatal.

${ }^{25}$ CRYM. Boletín Informativo. Buenos Aires 1936. 
c) Fijar las condiciones de elaboración, sanidad e higiene del producto en el ciclo de la zafra hasta su entrega al consumo con el asesoramiento de las reparticiones públicas especializadas.

d) Reglamentar la época en que debe efectuarse la poda y vigilar el cumplimiento de la prohibición de la poda prematura.

e) Realizar y compilar la estadística de la producción, elaboración y consumo del producto y su comercialización.

f) Propender a la construcción de secaderos y noques al desarrollo de crédito yerbatero para la producción, almacenamiento y expendio del producto y a la mejor organización de los productores a fin de facilitar su acceso directo y sin trabas a los mercados, para lo cual deberán establecerse organizaciones de concentración y ventas de la que no podrá salir yerba canchada sin certificado de análisis.

g) Establecer la clasificación de la yerba y propender a la mejora de su calidad y homogeneidad.

h) Asesorar al Poder Ejecutivo en todas las cuestiones relativas al régimen económico y técnico de la industria y sugerir al mismo las medidas tendientes a su mejoramiento.

i) Aplicar y percibir, previa autorización del Poder Ejecutivo, un impuesto móvil interno, que por el presente artículo se establece, uniformemente sobre toda yerba elaborada, así sea importada o molida en el país.

Con el objetivo de regular la oferta acorde a las necesidades de consumo se crea por Decreto 83.816, de abril de 1936, el Mercado Concentrador de la Yerba Mate (MCYM). La principal función de esta institución consistía en realizar la venta de la yerba mate de los productores en el momento adecuado y al precio estipulado por la CRYM, además de facilitar al colono almacenamiento y transporte; como así también el pago de su producción y el otorgamiento de un crédito prendario financiado por el Banco de la Nación Argentina.

"El Mercado actuará exclusivamente como consignatario y, para mejor cumplir sus fines reguladores exigirá de los plantadores que le consignen su producción, una autorización para efectuar la venta en el momento y al precio que el organismo considere conveniente" "El mercado operará en base al crédito agrario prendario otorgado por el Banco de la Nación Argentina a la yerba mate consignada al organismo, sin prejuicio de aceptar otras consignaciones de este producto". ${ }^{26}$

${ }^{26}$ CRYM. Boletín Informativo. Buenos Aires 1936. 
Este fue el canal más importante para la comercialización de yerba mate; sin embargo y en forma paralela se desarrollan formas directas de comercialización entre productores, secaderos y molinos, dando origen al denominado mercado libre, es decir, sin la intervención estatal. Para controlar la actividad, la CRYM crea el Registro Nacional de Yerbateros en el que deben inscribirse, con carácter obligatorio, los elaboradores, los importadores y acopiadores de yerba sin desecar (verde) y se crea, además, un Registro Nacional de Plantadores en el que se inscriben todos los cultivadores de yerba mate del país y cuya reglamentación deberá propender al mejor cumplimiento de la ley. Por intermedio del Decreto Reglamentario 77.473 de 1936, se propone el cobro de un "impuesto móvil" con el objetivo de compensar al productor entre costo y precio de venta, cuando esta última operación no logre cubrir los gastos del productor, como así también destinar ese impuesto a gastos de la CRYM. La compensación a los yerbateros se efectuaría a través del Banco de la Nación en las sucursales ubicadas en las zonas productoras, previo registro de las operaciones de venta.

De acuerdo con el artículo $8^{\circ}$ del Decreto del Poder Ejecutivo 23.886 del 20 de junio de 1933, se exigía que la yerba mate producida, que circule y se consuma en el país, reúna las mismas condiciones establecidas para las importadas. Para la importación de este producto se habilitan los puertos de Buenos Aires, Rosario, Santa Fe, Corrientes, Formosa, Posadas, Paso de los Libres y Bahía Blanca, permitiendo el ingreso de yerba mate canchada y molida acorde a los requerimientos de la CRYM, aunque las mismas quedan eximidas de la presentación del certificado de sanidad de origen ${ }^{27}$ Las gestiones de la Comisión Reguladora influyen en la elevación de los precios que percibía el productor, en la disminución -aunque leve- de las importaciones de yerba mate desde Brasil, como así también en la regulación de los stocks.

\section{1- Primera etapa de intervención estatal 1930- 1943}

Tres años después de haberse creado la CRYM se decide, debido a la situación de desequilibrio, limitar la producción nacional de yerba mate, considerando que dicha medida garantizaría la compensación de la producción, como así también los gastos de mantenimiento de los yerbales y la amortización e intereses de los capitales invertidos. El límite a la producción se impone en abril de 1938 por decreto 2992 del Poder Ejecutivo. El Presidente de la Nación Argentina en acuerdo de Ministros decreta: Art. 1: Limitase la producción de yerba mate canchada del año 1938 a cada plantador nacional. ${ }^{28}$

La limitación implicaba:

a) Un cuarenta por ciento (40\%) de reducción directa, en base al censo de 1937 , a todo yerbal que tenga más de un ochenta por ciento $(80 \%)$ de plantas en plena producción, considerándose como tales a las de implantación no menor de ocho años.

b) Igual reducción de un cuarenta por ciento $(40 \%)$ de la probable cosecha que establezca su tasación, a los yerbales en evolución, considerándose como

\footnotetext{
${ }^{27}$ CRYM. Boletín Informativo. Buenos Aires 1936.
}

${ }^{28}$ CRYM. Boletín Informativo. Buenos Aires 1938. 
tales los que tengan menos de ochenta por ciento $(80 \%)$ de plantas en plena producción.

c) Reducción de un 40 por ciento (40\%), previa tasación a los yerbales en plena producción que no hubiesen cosechado en el año 1937.

En 1939 se otorgan 8.129 certificados de habilitación de cosecha por un total de 64.533.726 kilogramos quedando 189 yerbales, de los 8.138 inscriptos en el Registro Nacional de Plantadores, sin adjudicación de cosecha por falta de capacidad productiva. A 1.569 productores les fueron asignados los mismos cupos que le correspondieron para 1938, por tratarse de cantidades que no sobrepasaban los 1.800 kilogramos y ser yerbales estacionarios; 3.438 productores recibieron certificados por un kilaje superior a los que les correspondían en 1938, por tratarse de yerbales en evolución cuyo aumento por las plantas es superior a las reducciones aplicadas; 3.122 productores recibieron cupos inferiores a los de 1938, por tratarse de yerbales estacionarios con asignaciones superiores a 1.8000 kilogramos o en evolución, pero cuyos aumentos resultaron mayores a las reducciones correspondientes. A 559 productores se les adjudicó 500 grms, por plantas, por tratarse de yerbales constituidos íntegramente por planta de 4 años.

Cuadro $N^{\circ} 1$ : Cosecha adjudicada por radios de censo para la zafra 1939

\begin{tabular}{|c|c|c|}
\hline Radios & Número de yerbales & Cosecha adjudicada (Kg) \\
\hline \multicolumn{3}{|l|}{ MISIONES: } \\
\hline Capital & 46 & 2.431 .899 \\
\hline Apóstoles & 491 & 2.054 .338 \\
\hline Azara & 291 & 338.631 \\
\hline Bonpland & 458 & 2.250 .571 \\
\hline Candelaria & 87 & 861.538 \\
\hline Cerro Azul & 217 & 798.028 \\
\hline Cerro Corá & 179 & 816.863 \\
\hline Concepción de la Sierra & 171 & 1.764 .907 \\
\hline Corpus & 224 & 1.401 .537 \\
\hline Eldorado & 703 & 8.917 .340 \\
\hline Gobernador Roca & 196 & 1.808 .875 \\
\hline Itacuararé & 180 & 583.668 \\
\hline L.N. Alem & 966 & 3.328 .186 \\
\hline Mineral y Oro Verde & 50 & 2.216 .644 \\
\hline Montecarlo & 288 & 3.026 .766 \\
\hline Oberá & 2.288 & 10.820 .710 \\
\hline O. V. Andrade & 224 & 330.037 \\
\hline Puerto Rico & 135 & 618.135 \\
\hline Puertos Alto Paraná & 26 & 4.516 .760 \\
\hline San Ignacio & 105 & 2.447 .658 \\
\hline San Javier & 313 & 479.750 \\
\hline San José & 118 & 1.629 .227 \\
\hline Santa Ana & 177 & 1.863 .607 \\
\hline Santo Pipo & 188 & 5.710 .215 \\
\hline TOTAL MISIONES & 8.121 & 61.015 .890 \\
\hline CORRIENTES & 196 & 3.514 .183 \\
\hline TUCUMAN & 1 & 3.663 \\
\hline
\end{tabular}

Fuente: CRYM, Boletín Informativo, 1939 
En 1939 continúa la política de limitar la producción de yerba mate, argumentando que si bien las medidas de limitación de la cosecha de 1938 evitaron que se agravara el desequilibrio originado por la acumulación de sobrantes de zafras anteriores, no fueron suficientes para reducir. Debido a esta situación, el Presidente de la Nación en acuerdo con los ministros, decide mantener en vigencia las autorizaciones de cosechas acordadas por la CRYM en 1938.

Este contexto, dominado por la crisis yerbatera, obliga al productor misionero a iniciar el proceso de diversificación productiva, incorporando la producción del tung y el té, además de la yerba mate. Durante este proceso se registran periodos de expansión de los productos diversificados a medida que la actividad yerbatera planteaba cupos o limitaciones. La culminación del proceso yerbatero significa la expansión de las fronteras en 50.000 has. de nuevos cultivos que se agregan, acentuando el carácter de la chacra con producción diversificada (Bolsi, 1986). También es importante el cultivo de tabaco, la producción de Misiones subió superando levemente a la de Corrientes en la década de 1920. "Con excepción de 1928 -cuando la máxima producción fue obtenida por la provincia de Salta- en adelante Misiones y Corrientes compartirán la primacía en la producción nacional hasta mediados de la década del 60, en momentos en que el importante aumento que se produce en el consumo de cigarrillos rubios estimula la producción del Noroeste" (Barsky, 2001).

Aunque se registra un aumento en el consumo de yerba mate en 1940, se considera que no se debían superar los 70.000 .000 de kilogramos del producto canchado para no generar superproducción y mantener en vigencia el límite de la cosecha, en beneficio de los precios redituables.

Cuadro $N^{\circ}$ 2: Consumo de Yerba Mate en el país en kilogramos (año 1939 y primer trimestre de 1940)

\begin{tabular}{ccc} 
Meses & Año 1939 & Año 1940 \\
\hline Enero & 7.395 .158 & 9.167 .771 \\
\hline Febrero & 7.852 .615 & 13.437 .946 \\
\hline Marzo & 10.807 .032 & 9.318 .485 \\
\hline Abril & 9.425 .176 & \\
\hline Mayo & 9.392 .746 & \\
\hline Junio & 8.133 .266 & \\
\hline Julio & 8.166 .639 & \\
\hline Agosto & 8.570 .933 & \\
\hline Septiembre & 10.302 .763 & $\mathbf{3 1 . 9 2 4 . 2 0 2}$ \\
\hline Octubre & 9.656 .818 & \\
\hline Noviembre & 10.067 .512 & \\
\hline Diciembre & 10.034 .648 & $\mathbf{1 0 9 . 8 0 5 . 3 0 6}$ \\
\hline Totales &
\end{tabular}

Fuente: CRYM, Boletín informativo 1940

A pesar del establecimiento de cupos y limitaciones, se advierte el constante proceso de importación de yerba mate. Esta situación perjudicaba al productor nacional, 
que si bien percibía los fondos prendarios, no siempre los mismos se pagaban en tiempo y forma.

Cuadro $N^{\circ}$ 3: Importación de yerba mate por país de procedencia por kilogramos: molida y canchada (1940 y primer trimestre de 1941)

\begin{tabular}{ccccccc}
\hline Meses & $\begin{array}{c}\text { Importación } \\
\text { total de } \\
\text { Brasil }\end{array}$ & $\begin{array}{c}\text { Importación } \\
\text { total de Para- } \\
\text { guay }\end{array}$ & Total & $\begin{array}{c}\text { Importación } \\
\text { total de } \\
\text { Brasil }\end{array}$ & $\begin{array}{c}\text { Importación } \\
\text { total de Para- } \\
\text { guay }\end{array}$ & Total \\
\hline Enero & 2.133 .020 & 659.619 & 2.792 .639 & 1.509 .935 & 936.040 & 2.445 .975 \\
\hline Febrero & 1.662 .166 & 599.055 & 2.261 .221 & 1.393 .147 & 587.531 & 1.980 .678 \\
\hline Marzo & 1.469 .240 & 337.042 & 1.806 .282 & 1.006 .041 & 462.312 & 1.468 .353 \\
\hline Abril & 3.312 .802 & 776.448 & 4.089 .250 & & & \\
\hline Mayo & 2.796 .269 & 747.800 & 3.544 .069 & & & \\
\hline Junio & 2.820 .152 & 337.485 & 3.157 .637 & & & \\
\hline Julio & 3.022 .492 & 747.567 & 3.770 .059 & & & \\
\hline Agosto & 2.213 .318 & 669.398 & 2.882 .716 & & & \\
\hline Septiembre & 2.591 .439 & 836.621 & 3.428 .060 & & & \\
\hline Octubre & 1.881 .706 & 1.234 .156 & 3.115 .862 & & & \\
\hline Noviembre & 2.442 .261 & 1.061 .198 & 3.503 .459 & & & \\
\hline Diciembre & 1.198 .114 & 1.170 .686 & 2.368 .800 & & & \\
\hline Totales & $\mathbf{2 7 . 5 4 2 . 9 7 9}$ & $\mathbf{9 . 1 7 7 . 0 7 5}$ & $\mathbf{3 6 . 7 2 0 . 0 5 4}$ & $\mathbf{3 . 9 0 9 . 1 2 3}$ & $\mathbf{1 . 9 8 5 . 8 8 3}$ \\
\hline
\end{tabular}

Fuente: CRYM, Boletín informativo 1941

Uno de los instrumentos considerados fundamentales para superar la sobreproducción de yerba mate nacional proponía colocar en el mercado externo el excedente productivo, obteniendo réditos favorables. Juan Buelink, presidente de la S.A. Financiera e Industrial de Misiones, en un viaje que realizó por EE.UU. y Europa afirmaba que "en el oeste de los Estados Unidos, en California y estados vecinos se han vendido en el año 1935 importantes cantidades de yerba mate argentina al precio de \$9,93 el kilo al abrigo de la propaganda efectuada por una firma norteamericana de importación del artículo". ${ }^{29}$ Alemania importó $1.332 .000 \mathrm{~kg}$ en el año 1932, demostrando alto índice de consumo, debido a que durante la Primera Guerra Mundial (1914- 1918), el ejército alemán sustituyó el té que bebían las tropas por yerba mate. ${ }^{30}$

\footnotetext{
${ }^{29}$ Revista de Economía Argentina: Como podría ser dominada nuestra industria yerbatera. Buenos Aires. 1938, número 241 Ob. Cit. Pp. 217- 218.

${ }^{30}$ Revista de Economía Argentina: El problema de la yerba mate. Buenos Aires 1940, número 261
} 
Rodríguez. Estado y producción: la actividad yerbatera en el territorio nacional de Misiones (1926- 1953)

Cuadro $N^{\circ} 4$ : Exportación de yerba mate en kilogramos (1940-1942)

\begin{tabular}{cccc}
\hline Países de destino & Año 1940 & Año 1941 & Año 1942 \\
\hline Bolivia & 64.418 & 86.721 & 64.727 \\
\hline Chile & 17.778 & 26.890 & 87.378 \\
\hline Ecuador & ---- & 500 & 13.240 \\
\hline EE.UU & 10.627 & 11.015 & 657.423 \\
\hline Perú & 3.100 & 6.326 & 2.865 \\
\hline Reino Unido & 12.761 & 4.996 & 133 \\
\hline Siria & 12.460 & ------- & 7.600 \\
\hline Suiza & 1.383 & ----- & 49.729 \\
\hline Unión Sudafricana & ----- & ----- & 1.622 \\
\hline Uruguay & 920 & 1.640 & 1.769 \\
\hline Otros países & 9.039 & 3.183 & $\mathbf{8 8 6 . 5 0 6}$
\end{tabular}

Fuente: CRYM, Boletín informativo, 1943

A partir de 1942, y mediante el Decreto 127.748 del Ejecutivo Nacional se amplían los cupos de cosecha, "al cumplirse el quinto año de cosechas limitadas, se ha tenido la satisfacción de acordar en sensible aumento a la producción nacional del año en curso. Esta medida corrobora la eficacia de la regulación impuesta a la yerba mate, por cuanto no solo se ha conseguido eliminar el stocks de arrastre, sino que también se ha logrado ir beneficiando a los plantadores nacionales con los aumentos paulatinos del consumo", ${ }^{31}$ que está asociado al crecimiento de la población, que demanda $71 / 2 \mathrm{~kg}$ de yerba por persona entre 1920 y 1940 (Bolsi, 1986). El mercado interno refuerza su importancia en la economía argentina en tiempos de la Segunda Guerra Mundial.

El aumento de los cupos favorece el incremento de las cosechas que, sin embargo, chocarían con otra dificultad: las pésimas condiciones de los caminos y los medios de transporte, que no logran cargar todo lo producido, quedando almacenadas grandes cantidades en los galpones de las zonas productoras. Por esta razón, se establece para el año 1943 el periodo de cosecha entre el $1^{\circ}$ de mayo y el 15 de octubre, modificándose el que se iniciaba en marzo y limitando la producción con las mismas normas de la cosecha de 1938; es decir "que se prescinde para el corriente año de la ampliación extraordinaria y especial del $20 \%$ que se acordó el año anterior ya iniciada la cosecha". ${ }^{32}$ La importación de yerba mate desde Brasil y Paraguay continuaba, alcanzando para 1942, a los 30.904.399 kilogramos. Hasta el mes de mayo de 1943 se contabilizaron 13.976.518 kilogramos. El ingreso de yerba mate canchada de origen nacional a los molinos para el mismo periodo fue de $86.271 .766 \mathrm{~kg}$ para 1942 y 32.954 .763 durante los primeros cinco meses de $1943 .{ }^{33}$

\footnotetext{
${ }^{31}$ CRYM. Boletín Informativo. Buenos Aires, 1942.

${ }^{32}$ CRYM. Boletín Informativo. Buenos Aires, 1943.

${ }^{33}$ CRYM. Boletín Informativo. Buenos Aires, 1943.
} 


\subsection{Nueva etapa de intervención: 1943- 1950}

A partir de 1943, se inicia en la Argentina una nueva etapa caracterizada por un tipo de Estado con perfil dirigista y planificador, en el que se destaca la figura de Juan Domingo Perón. En términos económicos, se acentúa el proceso de industrialización sustitutivo de importaciones, que significó una acelerada urbanización, acentuando el ya histórico desequilibrio regional, y la conformación de un nuevo proletario industrial sometido a un proceso de acumulación capitalista sin distribución de ingresos, y por lo tanto cargado de reivindicaciones no satisfechas (Lattuada, 1986).

Es en este periodo que la Comisión Reguladora de la Yerba Mate sufriría modificaciones. Las medidas directas tomadas especialmente en el gobierno de Perón (1946- 1955) con respecto a la actividad estuvieron relacionadas, luego de la nacionalización del Banco Central de la República Argentina (1946), al sometimiento de la superintendencia de esta máxima entidad financiera, que afectó también a la Comisión Reguladora de la Yerba Mate (Decreto 8403/46). Sin embargo, la situación durará hasta que el Decreto 11.344/46 disponga que la Dirección de la Yerba Mate sea integrada a la Dirección General de Comercio de la Secretaria de Industria y Comercio de la Nación, para luego ser transferida directamente a esta Secretaria por Decreto 3.900/49. Un año más tarde, tanto las funciones de la Dirección de la Yerba Mate como las de la CRYM, por el Decreto 7.990/50, conformarían la Comisión Nacional de Yerba Mate (CNYM) (Magán, 2008).

En 1947 el informe de la Dirección de Estadísticas y Censos registró un ingreso en los molinos del país de 133.359 toneladas de yerba mate canchada. Una cifra que señala un aumento del 7,2\% en relación al año anterior.

Cuadro $\mathrm{N}^{\circ}$ 5: Ingreso de yerba mate canchada a los molinos

\begin{tabular}{ccc} 
Orígenes & Absoluta en toneladas & Relativa \% \\
\hline Nacional & 103.826 & 77,9 \\
\hline Brasileña Matto Grosso & 10.424 & 7,8 \\
\hline Brasileña Atlántico & 14.187 & 10,6 \\
\hline Paraguaya & 4.922 & 5,7 \\
\hline TOTALES & $\mathbf{1 3 3 . 5 5 9}$ & $\mathbf{1 0 0}$ \\
\hline
\end{tabular}

Fuente: Revista Economía Argentina Nº 358 año 1948

Esta etapa se caracteriza por el aumento de una de las instituciones que aglutina a una gran parte de los pequeños y medianos productores yerbateros: las cooperativas. El cooperativismo fue fomentado por la Comisión Reguladora:

"considerando que la organización de los productores es fundamental para el desarrollo económico de sus actividades, la Comisión Reguladora aconseja y apoya decididamente la agremiación de los mismos en cooperativas agrícolas". ${ }^{34}$

\footnotetext{
${ }^{34}$ CRYM. Boletín Informativo. Buenos Aires, 1938.
} 
La relación del gobierno y el movimiento cooperativo agrario se centran en la libre comercialización de la producción agropecuaria, sumándose desde 1950 la denominada vuelta al campo (Girbal- Blacha, 2004) que orienta el rumbo de la economía hacia el sector agropecuario, buscando bajar los costos de intermediación. El Estado mantiene relación con el movimiento cooperativo en dos planos: en tanto representación de los productores agrarios agrupados en las cooperativas y en la función estatal de fomento, supervisión y control en reguardo de los intereses de la comunidad; una función ejercida por la Dirección Nacional de Cooperativas, dependiente primero del Ministerio de Agricultura y desde 1948 del Ministerio de Industria y Comercio de la Nación. Se perciben también los créditos otorgados por el gobierno nacional a estas entidades por intermedio del Banco Nación Argentina, a un interés del 5\%, apreciándose el rol que tienen estas instituciones en la política de redistribución ingreso del gobierno de Juan Perón (Girbal Blacha, 2011).

Las prohibiciones de efectuar nuevas plantaciones que regían desde 1936, más las limitaciones de cosecha que se efectuaron a partir de 1938 -con alternancias y aumentos de cupos de producción- generaron la necesidad de renovar los cultivos, ${ }^{35} \mathrm{y}$ en 1944 la entonces Dirección de Yerba Mate, mediante un estudio ${ }^{36}$ realizado, afirma que si no se renovaban las plantaciones la producción para el año 1959 no llegaría a cubrir la demanda nacional. ${ }^{37} \mathrm{La}$ autorización para realizar nuevas plantaciones fue aprobada por el Poder Ejecutivo Nacional ante las gestiones que se realizaron en el año 1953, que se plasmaron recién dos años después con el inicio de nuevas plantaciones, ${ }^{38}$ durante la vigencia del $2^{\circ}$ Plan Quinquenal y una vez superada la crisis económica de 1952.

\section{Consideraciones finales}

El accionar del Estado Nación en Misiones implicó la ocupación del espacio y la delimitación de límites fronterizos. Actuó además como construcción política e identitaria y, al mismo tiempo, como factor económico, en tanto supuso la expansión de la frontera agrícola, que permitió incorporar tierras al sistema productivo, principalmente a partir de la yerba mate. A pesar de la presencia estatal, las fronteras se manifestaron permeables y los vínculos e interconexiones entre los pobladores de Brasil, Paraguay y Misiones devienen en un particular sistema de relaciones, que superan las barreras nacionales generando una región que escapa a dichos límites (Secreto, 2012). La presencia de yerba mate en los tres países determinó históricamente las relaciones comerciales (legales o no) entre estos territorios.

El proceso colonizador establece y consolida una estructura burocrática. Aún en un ámbito de ciudadanía limitada como el de los Territorios Nacionales, el Estado se preocupa por interpelar y configurar a los habitantes; acciones que se conjugan con el

\footnotetext{
${ }^{35}$ La yerba mate tarda cuatro años en entrar en producción, pasados 20 años de ello la producción por planta pierde rendimiento en calidad y cantidad de $\mathrm{kg}$.

${ }^{36}$ Dicho estudio se volvió a realizar en 1951, confirmando la necesidad de replantar.

${ }^{37}$ CRYM. Boletín Informativo. Buenos Aires. 1957-1958, Ob. Cit. Pp. 9- 13.

${ }^{38}$ CRYM. Boletín Informativo. Buenos Aires. 1957- 1958, Ob. Cit. Pp. 15.
} 
arraigo de nuevos individuos en esas tierras. Al interior de estas estructuras se consolida un ethos característico que también conforma el entramado de relaciones de poder e influye sobre el ámbito local. La inmigración es otro actor de activa participación en la colonización yerbatera que integran estas tierras al sistema productivo agrícola con un cultivo que es marginal dentro del modelo agroexportador imperante. Es un proceso de selección y cooptación de nuevos individuos como parte de la población que comienza a constituirse (Rodríguez y Blacha, 2013). A partir de 1926 -con el decreto de residencia firmado por el presidente radical Marcelo T. de Alvear- se configura un sistema productivo, que también modela el territorio con la afluencia de inmigrantes a quienes adjudican tierras en carácter de propietarios, aunque, como se ha enunciado, la titularización de las parcelas resultaba un proceso arduo al que no todos pudieron acceder.

Las medidas estatales en torno a la producción yerbatera responden a la necesidad del contexto y al inicio de un Estado interventor, que se transforma en dirigista desde mediados de los años ' 40 y que -con diferentes matices- se extiende hasta 1955. La CRYM actuó como organismo interventor -durante la etapa en que Misiones fue Territorio Nacional esta institución tenía su sede en Buenos Aires y no en el área productora- y junto al Mercado Consignatario intentaron sostener un precio capaz de cubrir los costos del productor más allá de las fluctuaciones del mercado; aunque en forma paralela a dicha entidad, existían operaciones directas de comercialización entre productores, secaderos y molinos en un mercado libre, donde no intervenía el Estado como intermediario. De todos modos, las desigualdades regionales perduran y el modelo agroexportador imponen sus reglas.

\section{Fuentes utilizadas}

Comisión Reguladora de la Yerba Mate (CRYM): Boletín Informativo. Buenos Aires. Selección desde 1936 a 1943 - 1957/58.

Justo, A. P. 1937. La Obra del Gobierno Argentino 1932- 38. Momento Político Latinoamericano. Editores Ernesto César Rosasco- Antonio Carlos Ferro. Segunda Edición. Buenos Aires.

Ministerio de Economía y Finanzas Públicas. Secretaria de Política Económica. Subsecretaria de Programación Económica. 2011. Complejo yerbatero. Serie: Producción Regional para Complejos Productivos.

\section{Publicaciones de época}

Coni, E. 1929. "La yerba mate argentina y la fraternidad internacional". En Revista de Economía Argentina $\mathrm{N}^{\circ} 119$.

Daumas, E. 1930. El problema de la Yerba Mate. Publicación editada por la Asociación Argentina de Plantadores de Yerba Mate. Buenos Aires. 
Niklison, J. 1914. Informe sobre las condiciones de trabajo en el Alto Paraná. Boletín del departamento Nacional del Trabajo $\mathrm{N}^{\circ}$ 26. Buenos Aires. Ministerio del Interior.

Revista de Economía Aregentina. 1928. La industria yerbatera argentina. Informe del Gobernador de Misiones. Buenos Aires. N 117, marzo.

Revista de Economía Aregentina. 1938. Como podría ser dominada nuestra industria yerbatera. Buenos Aires, $N^{\circ} 241$.

Revista de Economía Aregentina. 1940. El problema de la yerba mate. Buenos Aires, $\mathrm{N}^{\circ} 261$.

\section{Referencias bibliográficas}

Abinzano, R. C. 1985. "Procesos de integración en una sociedad multiétnica. La provincia argentina de Misiones (1880-1985)". Tesis doctoral (Inédita).Universidad de Sevilla, ESPAÑA.

Alcaraz, A. 2010. La navegación y las actividades económicas en el Alto Paraná (18801920) Posadas, Editorial Universitaria de Misiones EDUNAM.

Barsky, O. y Gelman, J. 2001. Historia del Agro Argentino: desde la conquista hasta comienzos del siglo XXI. Buenos Aires, Editorial Sudamericana.

Bartolomé, L. 2000. Los colonos de Apóstoles. Posadas, Editorial Universitaria de Misiones. UNAM.

Bartolomé, L. 1982. "Base social e ideología en las movilizaciones agraristas en Misiones entre 1971 y 1975" En: Desarrollo Económico. Revista de Ciencias Sociales. Buenos Aires. IDES N ${ }^{\circ} 85$ Vol. 22. Abril- Junio.

Bartolomé, L. 1975. "Colonos, plantadores y agroindustrias. La explotación agrícola familiar en el sudeste de Misiones". En: Desarrollo Económico, Revista de ciencias sociales. Julio-septiembre.

Bolsi, A. 1986. "Misiones. Una aproximación geográfica al problema de la yerba mate y sus efectos en la ocupación del espacio y el poblamiento". En: Folia Histórica del Nordeste $N^{\circ} 7$. Resistencia.

Caferata, A.; De Santos, A. Tesoriero, G.; Brodershon, V., y Slutzky, D. 1975. Formación y desarrollo de las estructuras agrarias regionales: Misiones y Formosa. Consejo Federal de Inversiones (CFI), Diagnóstico de la Estructura Social de la región NEA, Bs. As.

Cárcano, M. A. 1972. Evolución histórica del régimen de la tierra pública 1810- 1916. Argentina, EUDEBA.

De Sagastizabal, L. 1984. La yerba mate y Misiones. Historia Testimonial Argentina. Documentos Vivos de Nuestro Pasado. Buenos Aires. CEAL.

Girbal Blacha, N. 1995. "Estado, modernización azucarera y comportamiento empresario en Argentina (1876- 1914)". En CAMPI Daniel (compilador) Estudios sobre la historia de la industria azucarera argentina I. San Miguel de Tucumán. Facultad de Ciencias Económicas (UNT). 
Girbal Blacha, N. 2004. "Organización cooperativa agraria y política gubernamental en la Argentina Peronista 1946- 1955”. En: Signos Históricos. Distrito Federal. México. Universidad Autónoma Metropolitana Iztapalapa. No 12. JulioDiciembre.

Girbal Blacha, N. 2011. Vivir en los márgenes. Estado, politicas públicas y conflictos sociales. El Gran Chaco Argentino en la primera mitad del siglo XX. Rosario, Ediciones Prohistoria.

Gortari, J. (Comp.). 2007.: De la tierra sin mal al tractorazo: Hacia una economía política de la yerba mate. Posadas: Editorial Universitaria de Misiones.

Jaquet, H. E. 2001. En otra Historia. Posadas, Editorial Universitaria de Misiones.

Kaner, M. 1999. Apuntes históricos sobre la yerba mate. Posadas, Editorial Universitaria UNAM.

Lattuada, M. 2006. Acción Colectiva y corporaciones agrarias en la Argentina. Transformaciones institucionales a fines del siglo XX. Buenos Aires, Universidad Nacional de Quilmes Editorial.

Lattuada, M. 1986. La política agraria peronista (1943- 1983) 1. Buenos Aires, Centro Editor de América Latina.

Magán, María Victoria. 2008. “¿Regulación o Crisis? La Influencia de la Comisión Reguladora de la Yerba Mate en los ciclos yerbateros 1924- 2002”. En: Pasado y Presente en el agro argentino. Buenos Aires, Ediciones Lumiere S.A.

Manzanal, M. 2014. "Desarrollo. Una perspectiva crítica desde el análsis del poder y del territorio" En: Realidad Económica. Revista de Ciencias Sociales. Buenos Aires. IADE. $\mathrm{N}^{\circ} 283$.

Obras de Lisandro de La Torre (1960). Tomo VI. Política Agraria y Municipal. Buenos Aires, Editorial Hemisferio, Segunda Edición.

Queiroz, P. R. 2012. “A Companhia Mate Laranjeira e seus fluxos mercantis (18911902)" En: III Congreso Latinoamericano de Historia Económica y XXIII Jornadas de Historia Económica. Bariloche Argentina.

Quién es Quién en la Argentina. (1939). Biografías contemporáneas. Buenos Aires, Editores Guillermo Kraft Ltda.

Quiroga, H. 1985. Estado, crisis económica y poder militar (1880-1981). Buenos Aires, Centro Editor de América Latina.

Rau, V. 2012. Cosechando yerba mate. Estructuras sociales de un mercado laboral agrario en el nordeste argentino. Buenos Aires, Ediciones CICCUS.

Rodríguez, L. y Blacha, L. 2013. "El biopoder en la colonización yerbatera de Misiones 1926- 1953". Documentos de Trabajo. Sociedad Española de Historia Agraria. España. DT SEHA N $13-08$.

Ruffini, M. 2007. La pervivencia de la República posible en los territorios nacionales. Poder y ciudadanía en Río Negro. Buenos Aires, Editorial Universidad Nacional de Quilmes.

Salvatore, R. 1986. "Control del trabajo y discriminación: el sistema de contratistas en Mendoza, Argentina, 1880- 1920”. En: Desarrollo Económico. Revista de Ciencias Sociales. Buenos Aires. IDES, N 102, Vol. 26, Julio- Septiembre. 
Secreto, V. 2012. Fronteiras em movimiento. História comparada-Argentina e Brasil no século $X I X$. Neterói. Editora da UFF.

Schamber, P. 2000. "Barajar y dar de nuevo. Consecuencia de la desregulación en el sector yerbatero". En: Revista Realidad Económica. Buenos Aires. IADE. N ${ }^{\circ}$ 169. Enero- Febrero.

Schiavoni, G. 1996. Colonos y Ocupantes. Parentesco, reciprocidad y diferenciación social en la frontera agraria de Misiones. Posadas, Editorial Universitaria.

Slutzky, D. (2011) Estructura social agraria y agroindustrial del nordeste de la Argentina: desde la incorporación a la economía nacional al actual subdesarrollo concentrador y excluyente. Instituto Argentino de Desarrollo Económico (IADE).

Thomaz de Almeida, R. y Mura, F. 2004. "Historia y territorio entre los guaraní e Mato Grosso do Sul, Brasil", Revista de Indias, Vol. LXIV, No 230.

Vanderlei Vazelesk, R. 2008. Cuestiones Agrarias en el varguismo y el peronismo. Una mirada histórica. 1 edición. Bernal, Universidad Nacional de Quilmes.

Zarrilli, A. 2007. "Quebracho y yerba mate. La producción regional del NEA frente a la crisis (1920-1940)". En: Girbal Blacha, N.; Ospital, S. y Zarrilli, A. Las miradas diversas del pasado. Las economías agrarias del interior ante la crisis de 1930. Buenos Aires, Edición Nacional. 